\title{
Time course of dementia following sepsis in German health claims data
}

Thomas Fritze, PhD, Gabriele Doblhammer, PhD, Catherine N. Widmann, Dipl-Psych, and Michael T. Heneka, MD

Neurol Neuroimmunol Neuroinflamm 2021;8:e911. doi:10.1212/NXI.0000000000000911

\section{Abstract}

\section{Objective}

We evaluated the short-, medium-, and long-term effects of sepsis on dementia incidence using German health claims data.

\section{Methods}

A total of 161,567 patients (65 years or older) were followed from 2004 to 2015 at quarterly intervals. Time since sepsis was categorized into 0 (the effective quarter of sepsis diagnosis), $1-8$, and $\geq 9$ quarters since the latest diagnosis of sepsis, taking into account admission to intensive care unit and controlling for delirium, surgery, age, sex, and comorbidities. Incident dementia was defined for all persons who did not have a validated dementia diagnosis in 2004 and 2005 and who received a first-time, valid diagnosis between 2006 and 2015.

\section{Results}

During the quarter of sepsis diagnosis, patients not admitted to intensive care had a 3.14-fold (95\% CI 2.83-3.49) increased risk, and those with intensive care stay had a 2.22 -fold (95\% CI: 1.83-2.70) increased risk of receiving an incident dementia diagnosis compared with patients without sepsis. The impact of sepsis on incident dementia remained in the following 2 years, remitting only thereafter.

\section{Conclusions}

For sepsis survivors, medium-term dementia risk remains elevated, whereas long-term risk may reach the level of those without sepsis, even after controlling for delirium. These findings encourage identifying modifiable components of hospital and rehabilitation care.

\author{
Correspondence \\ Dr. Heneka \\ michael.heneka@ukb.uni-bonn.de
}

From the German Center for Neurodegenerative Diseases (T.F., G.D., C.N.W., M.T.H.), Bonn; Institute for Sociology and Demography (G.D.), University of Rostock; and Department of Neurodegenerative Disease and Geriatric Psychiatry (C.N.W., M.T.H.), University of Bonn, Germany.

Go to Neurology.org/NN for full disclosures. Funding information is provided at the end of the article. 


\section{Glossary}

AOK = Allgemeine Ortskrankenkasse; HR = hazard ratio; ICD-10 = International Classification of Diseases, 10 th Revision; $\mathbf{I C U}=$ intensive care unit; WIdO = Wissenschaftliches Institut der AOK.

Systemic inflammation caused by microbial infection, hereafter referred to as sepsis, compromises the function of peripheral organs, but also affects the brain. Immediate changes in cognition and behavior on sepsis have been collectively described as sickness behavior and functionally analyzed in rodent models and human patients with sepsis. ${ }^{1}$ There is little doubt that an acute inflammatory reaction of the brain leads to transient EEG changes, cognitive dysfunction, and memory deficits. Far less clear, however, are the mid- to long-term consequences of sepsis for brain function and integrity. Particularly, the risk of developing neurodegenerative disorders in the subsequent months and years requires careful examination.

Adult sepsis survivors were found to be impaired with regard to a whole scale of activities of daily living and also displayed an increase in mild to moderate cognitive deficits. ${ }^{2}$ Similarly, patients who were followed after intensive care unit (ICU) treatment for sepsis were found to have persistent slowing of EEG activity and memory deficits along with hippocampal volume reduction. ${ }^{3}$ Research has shown that diagnosis of sepsis, delirium, or critical illness in general and major surgeries are each often followed by an acute lowered cognitive ability, which may or may not be permanent. ${ }^{4-7}$

How these events overlap or interact is a Gordian knot. To further delineate postseptic cognitive changes in patients with sepsis, we used a health insurance data set, identifying incident diagnoses of dementia in the months and years after sepsis and controlling for specific important diseases and medical events.

\section{Methods}

\section{Data}

We analyzed dementia incidence using routine claims data of the largest German statutory health insurance, the Allgemeine Ortskrankenkasse (AOK). In Germany, 70 million people insured via statutory health insurance (about $84.7 \%$ of the total population); about one-third of these are insured through the $\mathrm{AOK}^{8}$

A random, 5-year age-stratified sample of insurance claimants born in or before 1939 and who had at least 1 day of insurance coverage by the $\mathrm{AOK}$ in the first quarter of 2004 was drawn by the Scientific Institute of the AOK (Wissenschaftliches Institut der AOK [WIdO]). Access to health claims data is strictly regulated by law to ensure privacy of claimants. Insurees were, therefore, anonymized such that individuals cannot be identified. A unique person ID was allocated to retrospectively track individuals from 2004 through 2015 at quarterly intervals to establish a longitudinal sample. Data are available on a quarterly basis because outpatient physicians settle services with the Associations of Statutory Health Insurance Physicians (Kassenärztliche Vereinigungen) quarterly. Because information on the organization of medical visits and the specific date of diagnoses were unavailable, we used quarters as the reference parameter regarding the definition of commencement and duration of specific events. The data included complete records of inpatient and outpatient treatment received. Excluding those with inconsistent or missing information regarding date of birth, date of death, or sex, and those with a diagnosis of either dementia or sepsis in the first 2 observation years (2004 or 2005) yielded a study sample of 161,567 participants. This was not a study with human participants requiring an internal review board evaluation. The WIdO legally granted data access.

\section{Definition of dementia}

We used coding of the International Classification of Diseases, 10th Revision (ICD-10 codes) to define dementia diagnosis: G30, G31.0, G31.82, G23.1, F00, F01, F02, F03, and F05.1. We combined all ICD codes into 1 group named dementia. We applied an internal validation procedure to rule out falsepositive diagnoses. First, both outpatient verified diagnoses and inpatient discharge or secondary diagnoses were selected. Second, if dementia was diagnosed during the same quarter in both the inpatient and outpatient settings or if at least 2 physicians (general practitioners, neurologists/psychiatrists, and other specialists) diagnosed dementia within the same quarter for a given individual, the diagnoses were considered valid. Dementia diagnoses were also confirmed by cooccurrence over time during the entire observation period. Last, dementia diagnoses were considered valid in the case of death within the quarter of dementia diagnosis, which precluded validation by a second diagnosis. ${ }^{9,10}$

Incident dementia was defined as the first occurrence of a valid dementia diagnosis between 2006 and 2015. Using a period of at least 2 years (2004 and 2005) without a valid dementia diagnosis avoids confusion between incident diagnoses and prevalent cases with a history of dementia. ${ }^{9,11}$

\section{Independent variables}

We explored whether time since the latest sepsis diagnosis, ICU stay, delirium diagnosis, and surgery during the period of observation 2006-2015 affected the risk of dementia by creating periods defined as 0 (the effective quarter of diagnosis/ procedure), 1-8, and $>9$ quarters since the latest diagnosis or procedure, respectively. These time-varying variables allowed two issues to be accounted for. First, we were able to measure the time since the latest diagnosis or event. From a technical point of view, persons switch from 1 category to the next, depending on 
the quarters since the latest event of interest. This approach also implicates that persons switch back again to the category indicating the effective quarter of the recurring event.

For descriptive analyses, we differentiated more intervals for time since the latest sepsis diagnosis, delirium, ICU stay, or surgeries: quarter $0,1-2$ quarters, 3-4 quarters, $2,3,4,5$, or $\geq 6$ years (figure 1 ).

Sepsis was defined by ICD-10 code A41. Using both sepsis and admission to an ICU, we created a combined variable, which indicated whether a person had received a sepsis diagnosis in quarter $0,1-8$, or $\geq 9$ quarters before, and we considered whether a person received intensive care in the quarter of the sepsis diagnosis. Deliria were defined by ICD-10 codes F05 (F05.1 excluded) and F06.

Surgeries were defined according to the classification of operational procedures (Operationen-und Prozedurenschlüssel) ${ }^{12}$ an adaptation of the former version of the current International Classification of Health Interventions. ${ }^{13}$ The complete code range of chapter 5 (Surgical procedures) was used, thus including a wide range from small to extensive surgeries.

We adjusted for comorbidities and for age and sex. The following diseases were coded according to ICD-10 classification: diabetes mellitus (E10-E14); hypertension (I10-I13 and I15); hypercholesterolemia (E78.0); cerebrovascular diseases (I60-I69, G45, G46, and H34.0); depression (F32, F33, and F341); and Parkinson disease (G20-G22). All of the diagnoses used in this study were billing-relevant outpatient-verified diagnoses or inpatient discharge or secondary diagnoses by physicians.

\section{Statistical analysis}

Methods of survival analysis were applied to explore the risk of incident dementia diagnosis. Calendar time of the observation period (2006-2015) was used to operationalize the underlying process time. Exploring the effect of sepsis diagnosis and ICU stay on dementia incidence was performed with the help of Cox models. We controlled for the occurrence of delirium diagnoses, surgeries, and for sex and time-varying information on age, cerebrovascular diseases, diabetes mellitus, hypertension, hypercholesterolemia, depression, and Parkinson disease. Individuals were followed to the time of incident dementia diagnosis, death, withdrawal from insurance, loss to follow-up, or December 31, 2015, whichever occurred first.

Furthermore, we explored mortality following a sepsis diagnosis by using Kaplan-Meier survival curves. A 1:1-matched case-control design was applied, in which each patient with sepsis diagnosis was matched to 1 patient without sepsis diagnosis with respect to age, sex, and index date. The index date was the date of the latest sepsis diagnosis before death or censoring. Patients with sepsis were further stratified according to those with and without intensive care stays during the quarter of sepsis diagnosis $\left(\mathrm{N}=14,188 ; \mathrm{n}_{\text {no sepsis }}=\right.$ 7,094; $\left.\mathrm{n}_{\text {sepsis, no ICU }}=5,318 ; \mathrm{n}_{\text {sepsis, ICU }}=1,776\right)$.

\section{Data availability}

The WIdO has strict rules regarding data sharing because of the fact that health claims data are a sensible data source and have ethical restrictions imposed due to concerns regarding privacy. Anonymized data are available to all interested researchers on request. Interested individuals or an institution who wish to request access to the health claims data of the AOK, please contact the WIdO (webpage: wido.de/, email: wido@wido.bv.aok.de).

\section{Results}

The highest dementia incidence rate for each event group (latest sepsis diagnosis, ICU stay, delirium diagnosis, and

Figure 1 Dementia incidence rates by time since the latest sepsis diagnosis, ICU stay, surgery, and delirium diagnosis $(\mathrm{N}=161,567)$

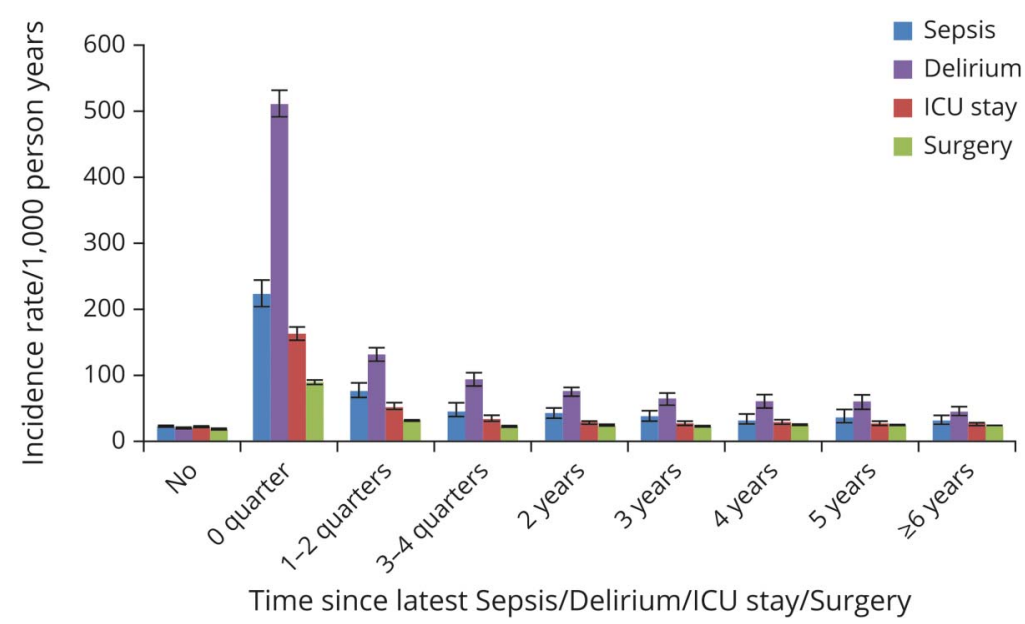

Source: Health claims data AOK 2004-2015; 95\% Cls. AOK = Allgemeine Ortskrankenkasse; ICU = intensive care unit. 
surgery) existed in the quarter (0) of the event itself. Incidence rates declined thereafter, but remained above the level of those without sepsis diagnosis, ICU stay, delirium diagnosis, or surgery, respectively (table 1, figure 1).

The incidence rate of dementia in the quarter of the sepsis diagnosis was disproportionally elevated among those aged 85 years and older (figure 2). This age gradient slightly attenuated over time since the latest sepsis diagnosis.

Table 2 presents the hazard ratios (HRs) for incident dementia diagnosis by time since sepsis diagnosis and distinguishes between patients who did or did not experience intensive care during the quarter of the sepsis diagnosis. It also

Table 1 Dementia incidence rates by time since the latest sepsis diagnosis, ICU stay, surgery, and delirium diagnosis $(\mathrm{N}=161,567)$

\begin{tabular}{|c|c|c|c|c|c|c|}
\hline Variable & Category & Exposures & $\begin{array}{l}\text { Incident } \\
\text { dementia }\end{array}$ & $\begin{array}{l}\text { Rate per } 1,000 \\
\text { person-years }\end{array}$ & LCI & UCI \\
\hline \multirow[t]{4}{*}{ Time since the latest sepsis diagnosis } & No diagnosis & $1,222,746.0$ & 27,838 & 22.77 & 22.50 & 23.04 \\
\hline & Quarter 0 & $2,072.0$ & 477 & 230.21 & 210.45 & 251.83 \\
\hline & $1-8$ quarters & $6,024.0$ & 328 & 54.45 & 48.86 & 60.67 \\
\hline & $\geq 9$ quarters & $5,856.5$ & 208 & 35.52 & 31.00 & 40.69 \\
\hline \multirow[t]{4}{*}{ Time since the latest ICU stay } & No ICU stay & $1,140,306.5$ & 24,949 & 21.88 & 21.61 & 22.15 \\
\hline & Quarter 0 & $6,425.5$ & 1,048 & 163.10 & 153.52 & 173.28 \\
\hline & $1-8$ quarters & $34,476.8$ & 1,310 & 38.00 & 35.99 & 40.11 \\
\hline & $\geq 9$ quarters & $55,489.8$ & 1,544 & 27.82 & 26.47 & 29.25 \\
\hline \multirow[t]{4}{*}{ Time since the latest surgery } & No surgery & $681,800.0$ & 12,741 & 18.69 & 18.37 & 19.01 \\
\hline & Quarter 0 & $32,173.9$ & 2,895 & 89.98 & 86.76 & 93.32 \\
\hline & 1-8 quarters & $196,827.0$ & 5,261 & 26.73 & 26.02 & 27.46 \\
\hline & $\geq 9$ quarters & $325,897.6$ & 7,954 & 24.41 & 23.88 & 24.95 \\
\hline \multirow[t]{4}{*}{ Time since the latest delirium diagnosis } & No diagnosis & $1,207,336.0$ & 24,710 & 20.47 & 20.21 & 20.72 \\
\hline & Quarter 0 & $4,000.7$ & 2,097 & 524.16 & 502.20 & 547.08 \\
\hline & $1-8$ quarters & $13,556.5$ & 1,364 & 100.62 & 95.42 & 106.10 \\
\hline & $\geq 9$ quarters & $11,805.3$ & 680 & 57.60 & 53.43 & 62.10 \\
\hline \multirow[t]{8}{*}{$\begin{array}{l}\text { Time since the latest sepsis diagnosis by ICU stay in } \\
\text { quarter of sepsis diagnosis }\end{array}$} & $\begin{array}{l}\text { No diagnosis, no } \\
\text { ICU stay }\end{array}$ & $1,216,886.5$ & 26,924 & 22.13 & 21.86 & 22.39 \\
\hline & $\begin{array}{l}\text { No diagnosis, } \\
\text { ICU stay }\end{array}$ & $5,859.5$ & 914 & 155.99 & 146.19 & 166.43 \\
\hline & $\begin{array}{l}\text { Quarter } 0 \text {, no ICU } \\
\text { stay }\end{array}$ & $1,679.8$ & 372 & 221.45 & 200.05 & 245.14 \\
\hline & $\begin{array}{l}1-8 \text { quarters, no } \\
\text { ICU stay }\end{array}$ & $4,880.8$ & 256 & 52.45 & 46.40 & 59.29 \\
\hline & $\begin{array}{l}9+\text { quarters no } \\
\text { ICU stay }\end{array}$ & $4,817.6$ & 169 & 35.08 & 30.17 & 40.79 \\
\hline & $\begin{array}{l}\text { Quarter } 0, \text { ICU } \\
\text { stay }\end{array}$ & 392.2 & 105 & 267.74 & 221.13 & 324.18 \\
\hline & $\begin{array}{l}1-8 \text { quarters, ICU } \\
\text { stay }\end{array}$ & $1,143.2$ & 72 & 62.98 & 49.99 & 79.35 \\
\hline & $\begin{array}{l}9+\text { quarters, ICU } \\
\text { stay }\end{array}$ & $1,039.0$ & 39 & 37.54 & 27.43 & 51.38 \\
\hline Total & & $1,236,698.5$ & 28,851 & 23.33 & 23.06 & 23.60 \\
\hline
\end{tabular}

Abbreviations: + = in person-years; $\mathrm{AOK}=$ Allgemeine Ortskrankenkasse; ICU = intensive care unit; $\mathrm{LCl}=95 \%$ lower $\mathrm{Cl} ; \mathrm{UCI}=95 \% \mathrm{upper} \mathrm{Cl}$. Source: Health claims data AOK 2004-2015. 
Figure 2 Dementia incidence rates by time since sepsis diagnosis and age

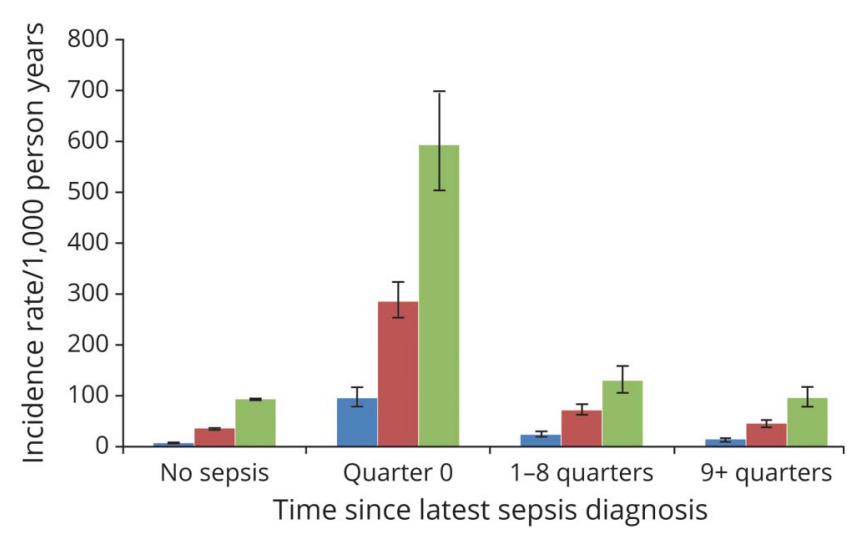

Source: Health claims data AOK 2004-2015; 95\% Cls. AOK = Allgemeine Ortskrankenkasse; ICU = intensive care unit.

shows the hazard ratios by time since delirium and surgery. All models were adjusted for comorbidities, age, and sex.

In model 1a, compared with cases without sepsis diagnosis, the hazard ratio of dementia was significantly increased during the quarter of sepsis diagnosis for both groups with $(\mathrm{HR}=$ 6.92, 95\% CI: 5.72-8.39) and without ICU stay ( $\mathrm{HR}=6.06$, 95\% CI: 5.47-6.72). The effects remained significant, albeit at a lower level, at 1-8 quarters after sepsis (with ICU: HR = 2.17, 95\% CI: 1.72-2.74; without ICU: $\mathrm{HR}=1.60$, 95\% CI: 1.41-1.81). There appeared to be no long-term effects of sepsis diagnosis having taken place 9 or more quarters ago.

We find an altered pattern in model 2 after additionally adjusting for time since the latest delirium diagnosis and surgery. Compared with cases without sepsis diagnosis, the dementia risk in the immediate quarter of sepsis was now highest for persons without ICU stay ( $\mathrm{HR}=3.14,95 \% \mathrm{CI}: 2.83-3.49)$ and lower for those with ICU stay (HR $=2.22,1.83-2.70)$. Medium-term effect continued to be significant (without ICU: $\mathrm{HR}=1.36,95 \% \mathrm{CI}: 1.20-1.54$; with ICU: $\mathrm{HR}=1.55$, 95\% CI: 1.23-1.96), whereas long-term effects are still nonexistent.

Model $1 \mathrm{~b}$ explores the effect of delirium on dementia incidence, which was highest in the immediate quarter of the delirium diagnosis ( $\mathrm{HR}=10.81,95 \% \mathrm{CI}: 10.33-11.32)$ but also remained significant, albeit at a lower level, in the medium $(\mathrm{HR}=2.33,95 \% \mathrm{CI}: 2.20-2.46)$ and longer term $(\mathrm{HR}=1.43$, 95\% CI: 1.32-1.54). Controlling for sepsis, ICU stay, and surgery, the effect of delirium was attenuated but remained significant, with the highest $\mathrm{HR}$ in quarter 0 ( $\mathrm{HR}=7.36,95 \%$ CI: 7.01-7.73) and dropping off thereafter (model 2).

Model 1c shows the effect of surgeries on the risk of dementia. Similar to sepsis and delirium, the hazard ratio of dementia was significantly increased during the quarter of surgery (quarter $0: \mathrm{HR}=3.66,95 \% \mathrm{CI}: 3.52-3.81$ ) and $1-8$ quarters after surgery $(\mathrm{HR}=1.13,95 \% \mathrm{CI}: 1.10-1.17)$. Effects slightly attenuated in model 2.

Calculating the number needed to harm from a model that distinguishes individuals who never had a sepsis from those who ever had one, we arrived at a figure of 51 for the median follow-up time of 7.625 years (table e-1, links.lww.com/NXI/ A350). This implies that 1 of 51 individuals having ever had sepsis receives an incident dementia diagnosis.

To compare the mortality patterns between patients with and without intensive care in the quarter of the sepsis diagnosis, we used Kaplan-Meier survival curves (figure 3). Compared with patients without ICU stay, the Kaplan-Meier-curve demonstrated a stark survival disadvantage of those with ICU stay during the quarter of the sepsis diagnosis. The parallel trajectory of the survival curves in the following quarters, however, suggested no long-term effect of ICU stay on mortality.

We performed sensitivity analyses using a subsample without patients with a delirium diagnosis and a subsample without patients with a delirium diagnosis, surgery, or ICU treatment during the observation period to examine the robustness of the results. We yielded consistent results for regression models and Kaplan-Meier survival analysis (table e- 2 and figure e-1, links.lww.com/NXI/A350).

\section{Discussion}

Next to acute and negative symptoms of sepsis on cognition and behavior, persistent cognitive deficits have been demonstrated, and an increased risk of developing neurodegenerative disorders has been postulated. ${ }^{14}$ Using a large sample of claims data obtained from the largest German statutory health insurance, we showed that as expected, delirium most frequently preceded with diagnosis of dementia. Next followed an independent effect of a prior diagnosis of sepsis, then a prior occurrence of an ICU stay and a previous surgery. For all of these clinical events, the incidence of dementia diagnosis was highest in the quarter during which the respective clinical event occurred. Thereafter incidence declined, but continued to persist at a raised level up to 2 years. This may suggest that the described clinical events all represent risk factors for a relatively rapid cognitive decline, even reaching the level of dementia within the first quarter.

A possible confounding factor could have been the higher medical attention that patients having these conditions received during hospitalization, and thus, previously unrecognized dementia cases may have been identified for the first time. Alternatively, clinical events such as perturbation of cerebral homeostasis during sepsis, delirium, procedures during ICU, or surgery may have accelerated clinically silent cases of predementia syndromes, moreover, because age represents the strongest risk factor for the development of dementia and all included patients were aged 65 years or 
older. This is supported by our finding that the immediate effect of sepsis on dementia diagnosis was largest among those aged 85 years and older. Last, documented delirium does not cover all cases of delirium, which actually occurred. Hence, the effect of delirium, which was coded, was higher than that of sepsis, which is not equivalent to the effect of delirium per se. Further, the observation period of 2 years without a diagnosis of either dementia or sepsis does not exclude the possibility that a case of sepsis occurred prior to 2004. Nor does it exclude a given claimant having had experienced previous ICU stays or surgical procedures.

Precise pathologic mechanisms could not be identified by our data set due to the diversity of microbial pathogens inducing sepsis, the heterogeneity of pathogenetic mechanisms underlying delirium, ${ }^{15}$ the divers interventions during an ICU stay, or the different surgical procedures. Despite this, all 4 clinical events were subsequently associated with the increased incidence of dementia either concurrently or thereafter. This is congruous with previous studies showing increased incidence of cognitive decline and dementia after sepsis, ${ }^{2,16,17}$ delirium, ${ }^{18-20}$ hospitalization for critical illness, ${ }^{4,5,21}$ and cardiac and noncardiac surgery. ${ }^{22,23}$ Possible mechanisms that may contribute to the sepsis-induced neurocognitive deterioration may include compromised microglial clearance function and subsequent accumulation of cerebral beta-amyloid, ${ }^{24}$ inflammatory changes at the synapse level ${ }^{25}$ or increased susceptibility to excitotoxic events after exposure to bacterial lipopolysaccharide. ${ }^{26}$ It is important to note that pathogenetic mechanisms have mostly been identified using rodent models, which in the case of sepsis share only a minor number of molecular signaling mechanisms with men. ${ }^{27}$ Thus, the underlying pathologic processes need to be further explored in particular in humanized models or the actual human cases itself. Of note, the incidence of dementia diagnoses following the described clinical events progressively lessened during the subsequent quarters, yet remained significantly greater than that of the respective case controls up to 2 years after the event. For delirium, the effect extended even beyond this period.

Table 2 Cox proportional hazard models for the complete sample with outcome incidence of dementia diagnosis

\begin{tabular}{|c|c|c|c|c|c|c|c|c|}
\hline & \multicolumn{4}{|c|}{ Model 1a-c } & \multicolumn{4}{|c|}{ Model 2} \\
\hline & HR & $p$ Value & LCI & UCl & HR & $p$ Value & LCl & UCI \\
\hline \multicolumn{9}{|c|}{ Time since the latest sepsis diagnosis by ICU stay in quarter 0} \\
\hline No diagnosis, no ICU (RG) & 1 & & & & 1 & & & \\
\hline No diagnosis, ICU & 4.70 & 0.000 & 4.40 & 5.02 & 1.93 & 0.000 & 1.80 & 2.08 \\
\hline Quarter 0, no ICU & 6.06 & 0.000 & 5.47 & 6.72 & 3.14 & 0.000 & 2.83 & 3.49 \\
\hline 1-8 quarters, no ICU & 1.60 & 0.000 & 1.41 & 1.81 & 1.36 & 0.000 & 1.20 & 1.54 \\
\hline 9+ quarters, no ICU & 1.14 & 0.101 & 0.98 & 1.32 & 1.07 & 0.400 & 0.92 & 1.24 \\
\hline Quarter 0, ICU & 6.92 & 0.000 & 5.72 & 8.39 & 2.22 & 0.000 & 1.83 & 2.70 \\
\hline 1-8 quarters, ICU & 2.17 & 0.000 & 1.72 & 2.74 & 1.55 & 0.000 & 1.23 & 1.96 \\
\hline 9+ quarters, ICU & 1.18 & 0.296 & 0.86 & 1.62 & 1.04 & 0.811 & 0.76 & 1.42 \\
\hline
\end{tabular}

Time since the latest delirium diagnosis

\begin{tabular}{lllllllll}
\hline No diagnosis (RG) & 1 & & & 1 & \\
\hline Quarter $\mathbf{0}$ & 10.81 & 0.000 & 10.33 & 11.32 & 7.36 & 0.000 & 7.01 & 7.73 \\
\hline $\mathbf{1 - 8}$ quarters & 2.33 & 0.000 & 2.20 & 2.46 & 2.29 & 0.000 & 2.16 & 2.42 \\
\hline 9+ quarters & 1.43 & 0.000 & 1.32 & 1.54 & 1.43 & 0.000 & 1.33 & 1.55 \\
\hline
\end{tabular}

Time since the latest surgery

\begin{tabular}{|c|c|c|c|c|c|c|c|c|}
\hline No surgery (RG) & 1 & & & & 1 & & & \\
\hline Quarter 0 & 3.66 & 0.000 & 3.52 & 3.81 & 2.39 & 0.000 & 2.28 & 2.50 \\
\hline 1-8 quarters & 1.13 & 0.000 & 1.10 & 1.17 & 1.06 & 0.000 & 1.03 & 1.10 \\
\hline 9+ quarters & 1.03 & 0.053 & 1.00 & 1.06 & 1.01 & 0.536 & 0.98 & 1.04 \\
\hline
\end{tabular}

Abbreviations: $\mathrm{AOK}=$ Allgemeine Ortskrankenkasse; $\mathrm{HR}=$ hazard ratio; $\mathrm{ICU}=$ intensive care unit; $\mathrm{LCl}=95 \%$ lower $\mathrm{Cl} ; \mathrm{RG}=$ reference group; $\mathrm{UCl}=95 \%$ upper $\mathrm{Cl}$. Source: Health claims data AOK 2004-2015; N = 161,567; all models adjusted for age, sex, cerebrovascular diseases, hypertension, diabetes, hypercholesterolemia, depression, and Parkinson disease; models 1a-c show the gross effect of the variable of interest unadjusted for the other information but adjusted for age, sex, cerebrovascular diseases, hypertension, diabetes, hypercholesterolemia, depression, and Parkinson disease; model 2 shows the joint effects of sepsis, ICU stay, delirium, and surgery. 


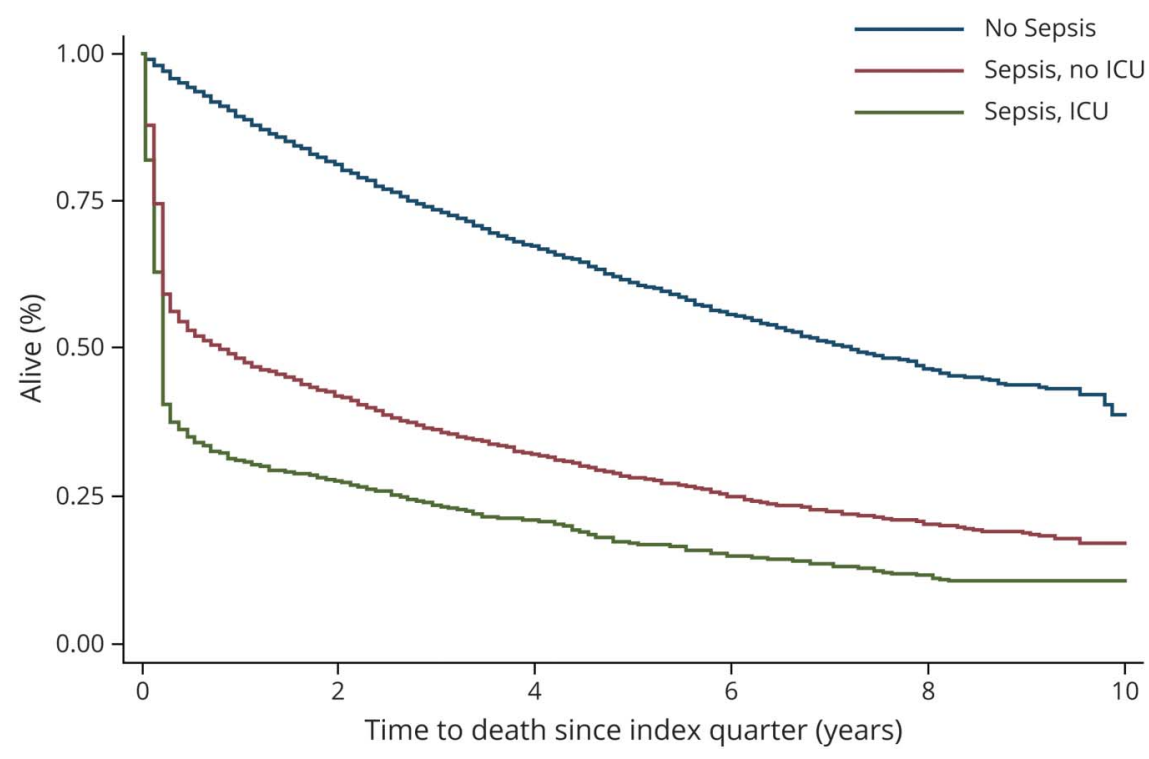

Zero signifies date of sepsis before censoring for cases and index date for controls $(\mathrm{N}=14,188)$. Source: Health claims data AOK 2004-2015; $n_{n}$ sepsis $=7,094 \mathrm{n}_{\text {sepsis, no ICU }}=5,318 \mathrm{n}_{\text {sepsis, ICU }}=$ 1,776. $\mathrm{AOK}=$ Allgemeine Ortskrankenkasse; ICU = intensive care unit.
The comparison of different age clusters (65-74, 75-84, and $85+$ years) revealed that dementia incidence after sepsis increased by age and that the oldest cluster was at highest risk of incidental dementia after sepsis, possibly indicating a contributing factor of immune senescence or reduced compensatory mechanisms of the brain to cope with the sepsis-caused challenge. ${ }^{28}$ Nevertheless, it seems important to note that the risk of developing dementia and, in particular, Alzheimer disease follows a similar age-dependent slope. When considering the decrease of incident dementia after the quarter of the respective clinical event, one may have expected a longer lasting effect of sepsis on the risk of developing dementia. One reason why sepsis may not show a more obvious effect on the incidence of dementia in the subsequent years may be the increased mortality of patients after initially surviving sepsis, which is in line with earlier epidemiologic studies of sepsisrelated mortality. ${ }^{29,30}$ Here, cases of hospitalization in an ICU showed increased mortality as compared to sepsis cases, which had not required intensive care. One underlying and frequent reason for ICU admission during sepsis is the occurrence of a multiorgan failure, which may reflect the severity of the infection, ${ }^{31}$ the frailty of the respective individual, and, certainly, a higher risk of cerebral involvement. ${ }^{32}$ The results may indicate a selection effect, with less cognitive-impaired and less frail individuals being healthy enough to survive the rigors of intensive care. Either way it is remarkable that sepsis increases mortality immediately in its aftermath but has no medium- and long-term consequences on survival.

One major methodological problem is to cleanly separate the effects of delirium, sepsis, and underlying acute or chronic diseases. ${ }^{20,33,34}$ However, the effect of sepsis on dementia risk in our data was independent of other critical events, age, sex, or comorbidities. In sensitivity analyses excluding patients with a delirium diagnosis, as a strong driver for dementia risk, we yielded consistent results for sepsis. Another problem is that we cannot differentiate between primary degenerative, progressive, and irreversible cognitive decline and potentially reversible dementia of secondary origin. The latter may be caused by physical diseases or injuries. ${ }^{35}$ For example, distinguishing delirium from dementia can be difficult. ${ }^{36}$ If such reversible dementia is assigned to one of the dementia diagnoses included in our study and persists over a longer period, our validation procedure may define these cases as valid dementia cases. Using the subsample without patients with delirium diagnosis, surgery or ICU treatment may partly exclude cases with potentially reversible dementia due to these critical events. Again, we yielded consistent results for sepsis.

The primary objectives of administrative health claims data are cost reimbursement and calculation, with implications for secondary data analyses. Not every diagnosis is relevant for the purposes of cost calculation. Thus, a patient's cognitive impairment or mild dementia might not be documented if no further treatment is given. The incidence of dementia will certainly be biased to higher ages, when the symptoms of the disease become more obvious. ${ }^{10}$ We thus cannot explore premorbid cognitive data as long as there is no diagnosis. Hence, it is difficult to disentangle whether such patients may in fact have had preexisting cognitive impairments or generally lower cognitive abilities before the major event, potentially even leading to a higher risk of admission to ICU or diagnoses such as sepsis or delirium. Our results may partly reflect such reverse causality. ${ }^{36-38}$ Preliminary analyses with sepsis diagnosis as the dependent variable revealed that ever experiencing a dementia diagnosis during the observation period is associated with an increased risk of incident sepsis diagnosis (results available on request), indicating such 
bidirectional relationships. Delirium is known to be undercoded in administrative data using ICD, ninth edition or ICD10 criteria compared with data using, e.g., Diagnostic and Statistical Manual of Mental Disorders, Fourth Edition criteria. $^{39,40}$ Delirium diagnoses, particularly in severe cases, are most often made in the inpatient setting where we are not able to define the specific type of physician who made the diagnosis. In general, such a diagnostic code is made either by a neurologist or psychiatrist. Furthermore, we are not able to define the severity of sepsis. Health claims data do not include clinical parameters, and clinical sepsis codes (R65.0! for sepsis and R65.1! for severe sepsis in 2005; R57.2 for septic shock in 2010) were introduced later and may not have been used consistently over time. In our study, we used ICD code A41, which may be associated with an underestimation of sepsis cases, but with a high positive predictive value. ${ }^{41,42}$

We are not able to explore the association between sepsis and a specific dementia type. Health claims data do not represent the actual distribution of specific dementia diagnoses. In the AOK data, $45 \%-50 \%$ of the dementia diagnoses were of unspecified dementia, and only $27 \%$ of dementia cases were diagnoses of Alzheimer disease dementia. That is in contrast to the prevalence of Alzheimer disease dementia $(60 \%-80 \%)$ in epidemiologic studies. ${ }^{43}$ The significantly different distributions by etiology compared with population-based cohort studies result from the lack of standardized criteria of diagnoses in claims data. The main reason for the different diagnosis pattern is that about $42 \%$ of dementia diagnoses are made by general practitioners, who are unable to identify the exact etiology of the disease. ${ }^{44}$ This is primarily attributable to the fact that in contrast to specialist care, general practitioners are not obliged to code the complete 5-digit ICD-10 code. Furthermore, often, computer-based practice information systems only require a documentation of 3 digits and add a ".9" for unspecified types of a disease. ${ }^{45}$ But even specialists such as neurologists and psychiatrists have been shown to classify $31 \%$ of their patients with dementia as having unspecified dementia. ${ }^{44}$ However, recent research revealed that single diagnoses of dementia disease, such as Alzheimer disease, become rarer with advancing age and that mixed pathologies prevail. ${ }^{46}$ We therefore used an overall indicator for dementia.

Dementia diagnoses in medical claims data are neither specific nor standardized, and a claims-based definition of dementia and other diagnoses is not the same as prospective clinical assessment. However, the prevalence and incidence based on AOK claims data fit well with other national and international studies. ${ }^{9,10}$ Furthermore, using formal medical diagnoses prevents recall bias by the patient. Health claims data do not provide lifestyle and medical information, such as intensity of former or current tobacco use, dietary habits, or body mass index, which could potentially affect the association between sepsis and dementia.

We analyzed a nationwide population-based data set with a large sample size that allowed investigating the relationship between sepsis and dementia. The analysis of health claims data avoids potential biases that often occur in population- based surveys. There is no bias arising from response behavior or self-selection, selection by the health care provider, or the study design. In particular, community dwelling and people living in nursing homes are included, with the latter usually missing in surveys. All of the data were legally made available in anonymous form, thereby eschewing any selection bias due to active volunteerism. In addition, medical diagnoses were documented, preventing recall bias by individual participants, and were validated, avoiding use of false-positive diagnoses.

Our observational study showed that for up to 2 years after sepsis, incidents of dementia doubled and even tripled compared with those without sepsis, after accounting for other clinical events, such as delirium. Hence, incident dementia may be precipitated by or perhaps even induced by sepsis, in addition to or in combination with other clinical events such as delirium, surgery, and/or intensive care stay. To our knowledge, this independent effect has not been shown for sepsis diagnosis until now. Further research using primary data analysis will need to consider factors ameliorating or rescuing patients from cognitive decline and dementia following these events. Focus should rest on medical therapies and interventions, premorbid cognitive ability, including cognitive reserve, psychiatric illness, physical rehabilitation and after care, and potential confluences of causal factors sepsis and delirium and neurodegeneration.

\section{Acknowledgment}

The authors thank Juergen-Bernhard Adler, Andreas Kloess, and Christian Guenster from the Scientific Research Institute of the AOK (Wissenschaftliches Institut der AOK, WIdO) for providing the data.

\section{Study funding}

This study was supported by a grant from the Deutsche Forschungsgemeinschaft (KFO177, TP8, Prof. Michael T. Heneka).

\section{Disclosure}

T. Fritze, G. Doblhammer, and C.N. Widmann report no disclosure relevant to the manuscript. M. Heneka acts as an advisory board member of IFM Therapeutics, Alector, Tiaki and Vigil Neuroscience. Go to Neurology.org/NN for full disclosures.

\section{Publication history}

Received by Neurology: Neuroimmunology \& Neuroinflammation April 30, 2020. Accepted in final form August 24, 2020.

Appendix Authors

\begin{tabular}{lll}
\hline Name & Location & Contribution \\
\hline $\begin{array}{l}\text { Thomas } \\
\text { Fritze, PhD }\end{array}$ & $\begin{array}{l}\text { German Center for } \\
\text { Neurodegenerative } \\
\text { Diseases, Bonn, Germany }\end{array}$ & $\begin{array}{l}\text { Designed and } \\
\text { conceptualized the study; } \\
\text { analyzed the data; } \\
\text { interpreted the data; and } \\
\text { drafted the manuscript } \\
\text { for intellectual content }\end{array}$ \\
& & \\
\hline
\end{tabular}


Appendix (continued)

\begin{tabular}{|c|c|c|}
\hline Name & Location & Contribution \\
\hline $\begin{array}{l}\text { Gabriele } \\
\text { Doblhammer, } \\
\text { PhD }\end{array}$ & $\begin{array}{l}\text { German Center for } \\
\text { Neurodegenerative } \\
\text { Diseases, Bonn, Germany; } \\
\text { University of Rostock, } \\
\text { Germany }\end{array}$ & $\begin{array}{l}\text { Designed and } \\
\text { conceptualized the study; } \\
\text { interpreted the data; and } \\
\text { revised the manuscript } \\
\text { for intellectual content }\end{array}$ \\
\hline $\begin{array}{l}\text { Catherine N. } \\
\text { Widmann, } \\
\text { Dipl-Psych }\end{array}$ & $\begin{array}{l}\text { Department of } \\
\text { Neurodegenerative } \\
\text { Disease and Geriatric } \\
\text { Psychiatry, Bonn, } \\
\text { Germany; German Center } \\
\text { for Neurodegenerative } \\
\text { Diseases, Bonn, Germany }\end{array}$ & $\begin{array}{l}\text { Interpreted the data and } \\
\text { revised the manuscript } \\
\text { for intellectual content }\end{array}$ \\
\hline $\begin{array}{l}\text { Michael T. } \\
\text { Heneka, MD }\end{array}$ & $\begin{array}{l}\text { Department of } \\
\text { Neurodegenerative } \\
\text { Disease and Geriatric } \\
\text { Psychiatry, Bonn, } \\
\text { Germany; German Center } \\
\text { for Neurodegenerative } \\
\text { Diseases, Bonn, Germany }\end{array}$ & $\begin{array}{l}\text { Conceptualized the study; } \\
\text { interpreted the data; and } \\
\text { drafted the manuscript } \\
\text { for intellectual content }\end{array}$ \\
\hline
\end{tabular}

\section{References}

1. Holmes C, Cunningham C, Zotova E, Culliford D, Perry VH. Proinflammatory cytokines, sickness behavior, and Alzheimer disease. Neurology 2011;77:212-218.

2. Iwashyna TJ, Ely EW, Smith DM, Langa KM. Long-term cognitive impairment and functional disability among survivors of severe sepsis. JAMA 2010;304:1787-1794.

3. Semmler A, Widmann CN, Okulla T, et al. Persistent cognitive impairment, hippocampal atrophy and EEG changes in sepsis survivors. J Neurol Neurosurg Psychiatry 2013;84:62-69.

4. Ehlenbach WJ, Hough CL, Crane PK, et al. Association between acute care and critical illness hospitalization and cognitive function in older adults. JAMA 2010;303: 763-770.

5. Pandharipande PP, Girard TD, Jackson JC, et al. Long-term cognitive impairment after critical illness. N Engl J Med 2013;369:1306-1316.

6. Steinmetz J, Siersma V, Kessing LV, Rasmussen LS, Group I. Is postoperative cognitive dysfunction a risk factor for dementia? A cohort follow-up study. Br J Anaesth 2013;110(suppl 1):i92-i97.

7. Tully PJ, Baker RA. Current readings: neurocognitive impairment and clinical implications after cardiac surgery. Semin Thorac Cardiovasc Surg 2013;25:237-244.

8. Doblhammer G, Fink A, Fritze T, Günster C. The demography and epidemiology of dementia. Geriatr Ment Health Care 2013;1:29-33.

9. Doblhammer G, Fink A, Fritze T. Short-term trends in dementia prevalence in Germany between the years 2007 and 2009. Alzheimers Dement 2015;11:291-299.

10. Doblhammer G, Schulz A, Steinberg J, Ziegler U. Demografie der Demenz. Bern: Verlag Hans Huber, Hogrefe AG; 2012.

11. Fritze T, Teipel S, Ovari A, Kilimann I, Witt G, Doblhammer G. Hearing impairment affects dementia incidence. An analysis based on longitudinal health claims data in Germany. PLoS One 2016;11:e0156876.

12. German Institute of Medical Documentation and Information (DIMDI). German procedure classification (Operationen- und Prozedurenschlüssel-OPS) [online] Available at: dimdi.de/dynamic/en/classifications/ops/index.html. Accessed May 24, 2020.

13. World Health Organization. International Classification of Health Interventions (ICHI) [online]. Available at: who.int/classifications/ichi/en/. Accessed May 24, 2020.

14. Widmann CN, Heneka MT. Long-term cerebral consequences of sepsis. Lancet Neurol 2014;13:630-636

15. Girard TD, Thompson JL, Pandharipande PP, et al. Clinical phenotypes of delirium during critical illness and severity of subsequent long-term cognitive impairment: a prospective cohort study. Lancet Respir Med 2018;6:213-222.

16. Davydow DS, Hough CL, Levine DA, Langa KM, Iwashyna TJ. Functional disability, cognitive impairment, and depression after hospitalization for pneumonia. Am J Med 2013; 126:615-624.e5

17. Kao LT, Sheu JJ, Lin HC, Tsai MC, Chung SD. Association between sepsis and dementia. J Clin Neurosci 2015;22:1430-1433.

18. Davis DH, Muniz Terrera G, Keage H, et al. Delirium is a strong risk factor for dementia in the oldest-old: a population-based cohort study. Brain 2012;135: 2809-2816.
19. Davis DH, Muniz-Terrera G, Keage HA, et al. Association of delirium with cognitive decline in late life: a neuropathologic study of 3 population-based cohort studies. JAMA psychiatry 2017;74:244-251.

20. Devore EE, Fong TG, Marcantonio ER, et al. Prediction of long-term cognitive decline following postoperative delirium in older adults. J Gerontol A Biol Sci Med Sci 2017;72:1697-1702.

21. Tate JA, Snitz BE, Alvarez KA, et al. Infection hospitalization increases risk of dementia in the elderly. Crit Care Med 2014;42:1037-1046.

22. Paredes S, Cortinez L, Contreras V, Silbert B. Post-operative cognitive dysfunction at 3 months in adults after non-cardiac surgery: a qualitative systematic review. Acta Anaesthesiol Scand 2016;60:1043-1058.

23. Lingehall HC, Smulter NS, Lindahl E, et al. Preoperative cognitive performance and postoperative delirium are independently associated with future dementia in older people who have undergone cardiac surgery: a longitudinal cohort study. Crit Care Med 2017;45:1295-1303.

24. Tejera D, Mercan D, Sanchez-Caro JM, et al. Systemic inflammation impairs microglial Abeta clearance through NLRP3 inflammasome. EMBO J 2019;38: e101064.

25. Weberpals M, Hermes M, Hermann S, et al. NOS2 gene deficiency protects from sepsis-induced long-term cognitive deficits. J Neurosci 2009;29:14177-14184.

26. Hewett SJ, Csernansky CA, Choi DW. Selective potentiation of NMDA-induced neuronal injury following induction of astrocytic iNOS. Neuron 1994;13:487-494.

27. Seok J, Warren HS, Cuenca AG, et al. Genomic responses in mouse models poorly mimic human inflammatory diseases. Proc Natl Acad Sci USA 2013;110:3507-3512.

28. Heneka MT, McManus RM, Latz E. Inflammasome signalling in brain function and neurodegenerative disease. Nat Rev Neurosci 2018;19:610-621.

29. Stevenson EK, Rubenstein AR, Radin GT, Wiener RS, Walkey AJ. Two decades of mortality trends among patients with severe sepsis: a comparative meta-analysis. Crit Care Med 2014;42:625-631.

30. Winters BD, Eberlein M, Leung J, Needham DM, Pronovost PJ, Sevransky JE. Longterm mortality and quality of life in sepsis: a systematic review. Crit Care Med 2010; 38:1276-1283.

31. Rohde JM, Odden AJ, Bonham C, et al. The epidemiology of acute organ system dysfunction from severe sepsis outside of the intensive care unit. J Hosp Med 2013;8: 243-247.

32. Fleischmann-Struzek C, Mikolajetz A, Schwarzkopf D, et al. Challenges in assessing the burden of sepsis and understanding the inequalities of sepsis outcomes between National Health Systems: secular trends in sepsis and infection incidence and mortality in Germany. Intensive Care Med 2018;44:1826-1835.

33. Avidan MS, Evers AS. Review of clinical evidence for persistent cognitive decline or incident dementia attributable to surgery or general anesthesia. J Alzheimers Dis 2011;24:201-216.

34. Crocker E, Beggs T, Hassan A, et al. Long-term effects of postoperative delirium in patients undergoing cardiac operation: a systematic review. Ann Thorac Surg 2016; 102:1391-1399.

35. Bello VME, Schultz RR. Prevalence of treatable and reversible dementias: a study in a dementia outpatient clinic. Dement Neuropsychol 2011;5:44-47.

36. Fong TG, Davis D, Growdon ME, Albuquerque A, Inouye SK. The interface between delirium and dementia in elderly adults. Lancet Neurol 2015;14:823-832.

37. Funder KS, Steinmetz J, Rasmussen LS. Methodological issues of postoperative cognitive dysfunction research. Semin Cardiothorac Vasc Anesth 2010;14:119-122.

38. Shah FA, Pike F, Alvarez K, et al. Bidirectional relationship between cognitive function and pneumonia. Am J Respir Crit Care Med 2013;188:586-592.

39. Bellelli G, Nobili A, Annoni G, et al. Under-detection of delirium and impact of neurocognitive deficits on in-hospital mortality among acute geriatric and medical wards. Eur J Intern Med 2015;26:696-704.

40. Kazmierski J, Kowman M, Banach M, et al. The use of DSM-IV and ICD-10 criteria and diagnostic scales for delirium among cardiac surgery patients: results from the IPDACS study. J Neuropsychiatry Clin Neurosci 2010;22:426-432.

41. Jolley RJ, Sawka KJ, Yergens DW, Quan H, Jette N, Doig CJ. Validity of administrative data in recording sepsis: a systematic review. Crit Care 2015;19:139.

42. Fleischmann-Struzek C, Thomas-Ruddel DO, Schettler A, et al. Comparing the validity of different ICD coding abstraction strategies for sepsis case identification in German claims data. PLoS One 2018;13:e0198847.

43. Schulz A, Doblhammer G. Aktueller und zukünftiger Krankenbestand von Demenz in Deutschland auf Basis der Routinedaten der AOK: current and future number of people suffering from dementia in Germany based on routine data from the AOK. In: Günster C, Klose J, Schmacke N, eds. Versorgungs-Report 2012: Schwerpunkt: Gesundheit im Alter. Stuttgart: Schattauer; 2012:161-175.

44. Doblhammer G, Fritze T. Month of birth and dementia late in life. Kolner Z Soz Sozpsychol 2015;67:217-240.

45. Horenkamp-Sonntag D, Linder R, Wenzel F, Gerste B, Ihle P. Prüfung der Datenqualität und Validität von GKV-Routinedaten. In: Swart E, Ihle P, Gothe H, Matusiewicz D, eds. Routinedaten im Gesundheitswesen Handbuch Sekundärdatenanalyse: Grundlagen, Methoden und Perspektiven. Bern: Verlag Hans Huber; 2014:314-330.

46. Rahimi J, Kovacs GG. Prevalence of mixed pathologies in the aging brain. Alzheimers Res Ther 2014;6:82. 


\section{Neurology \\ Neuroimmunology \& Neuroinflammation}

Time course of dementia following sepsis in German health claims data

Thomas Fritze, Gabriele Doblhammer, Catherine N. Widmann, et al.

Neurol Neuroimmunol Neuroinflamm 2021;8;

DOI 10.1212/NXI.0000000000000911

This information is current as of December 8, 2020

Updated Information \&

Services

References

Subspecialty Collections

Permissions \& Licensing

Reprints including high resolution figures, can be found at:

http://nn.neurology.org/content/8/1/e911.full.html

This article cites 41 articles, 3 of which you can access for free at: http://nn.neurology.org/content/8/1/e911.full.html\#\#ref-list-1

This article, along with others on similar topics, appears in the following collection(s):

All Cognitive Disorders/Dementia

http://nn.neurology.org//cgi/collection/all_cognitive_disorders_dementi a

Delirium

http://nn.neurology.org//cgi/collection/delirium

Information about reproducing this article in parts (figures,tables) or in its entirety can be found online at:

http://nn.neurology.org/misc/about.xhtml\#permissions

Information about ordering reprints can be found online:

http://nn.neurology.org/misc/addir.xhtml\#reprintsus

Neurol Neuroimmunol Neuroinflamm is an official journal of the American Academy of Neurology.

Published since April 2014, it is an open-access, online-only, continuous publication journal. Copyright

Copyright $\odot 2020$ The Author(s). Published by Wolters Kluwer Health, Inc. on behalf of the American

Academy of Neurology.. All rights reserved. Online ISSN: 2332-7812.

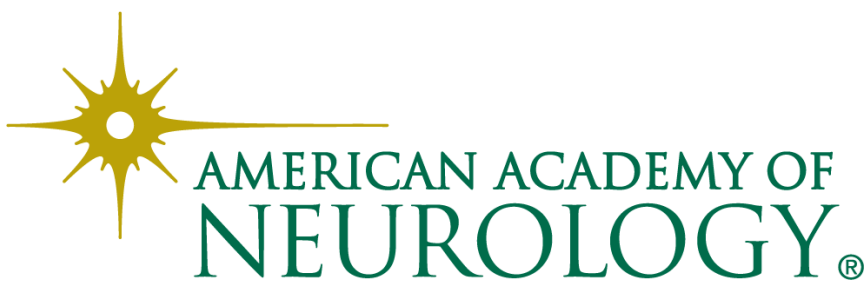

